\title{
A REDUNDANT POWER SUPPLY ARCHITECTURE FOR SELF- HEALING SUBSTATION USING ULTRACAPACITORS
}

\author{
Vasuki Soni ${ }^{1}$ \\ ${ }^{1}$ Vasuki soni, Engineer, ABB Global Industries and Services Ltd, Karnataka, Bangalore, India
}

\begin{abstract}
An Ultracapacitor storage based substation for the compensation of AC power loss or voltage drops in a Power distribution system is proposed. It allows input current feed in any voltage profile of the bay or a line. The system has been so designed that it would act as a compensating standby power source to be placed at weak points of stations, and with the substation devices like intelligent electronic devices (IED), Remote terminal unit (RTU) etc. instead of additional driving substations to support for auxiliary power. A dedicated power conversion arrangement with an adjoining control strategy for the regulation of voltage at the point of common coupling (PCC) in the event of strong noise or fluctuation is proposed. A detailed review has also been presented regarding the potentials of the Ultracapacitors to appreciate its performance. This paper also evaluates the current practices in the field of energy storage and compares Ultracapacitor with the technologies like Vented Lead acid batteries (VLAB) and other to assess the potential for replacing these with the new technologies. Also it is proved that the technology of Ultracapacitor is a strong contender for global market as reduces the carbon emissions and is eco-friendly. In this paper, the terminologies Ultracapacitor and EDLC are used interchangeably frequently but conceptually are same thing.
\end{abstract}

Keywords- Ultracapacitor, Electric double layer capacitor (EDLC), Protection Control and Monitoring (PCM),Leadacid battery, Hybrid energy storage system, Intelligent electronic devices (IED), MTBF (Mean time between failure), $\operatorname{MTTR}($ Mean time to repair (down time)).

\section{INTRODUCTION}

According to the IEC Standard 62040-3 [Edition 2] [21], the seamless redundant power supply or stand-by power supply systems can be described as an electronic power system. Its prime functionality is to provide informed continuity and quality power to a user device/equipment in the event of a partial or complete failure of the normal local source of power, which is generally the AC power from public power generation unit. This is achieved either by converting power from the typical local source and/or from any alternative form of stored energy to supply power to the user devices for a known period of time when the utility is non-available or highly unacceptable.

The user devices/equipment, normally referred to as the critical loads, may consist of either a single or number of equipment placed in a Utility or a building. This is the equipment which the user has defined to be supplied power that has appreciable continuity as well as acceptable quality compared to that which is typically available. The critical loads are predominantly some kind of data acquisition/processing device units, although it may be any other device say Communication equipment, control equipment or simply a monitoring unit. The stored form of energy to assist this load, usually in the form of batteries or other storage technologies, may be needed to supply power to the equipment for a specific duration which may even last for a moment or is continuous. This time interval is commonly known as stored energy time or stand-by time.
In the context of power systems, the most critical components are the protection, control and monitoring systems which are responsible to ensure proper and reliable working of the whole system. But the one entity is like an indifferent part of such systems which is so called as "Redundant power supplies". The ultimate dependability and reliability parameters of the substation is decided by the availability of the substation devices at the best of their health even at times of the AC power outage and redundant supplies ensure that the substation or the connected power systems keeps performing well in extreme conditions of Overloading, blackouts and complete failure etc.

The current scenario substations have numerous functionality and information which is quite useful for the substation supervision. These substations being heavily loaded with the technology and information have become a significant part. So each and every entity in the power systems which are handling such functionalities are need to protected and preserved. Hence as a prime concern, an efficient power storage device is required which is redundant and good enough to supply power to the substation unit in cases of Blackouts with a lot of charge density, capacity; resistant to fatigue i.e. life cycle should be fairly long even after rigorous use of device and is cost effective too.

So in the competition to come up as a good energy storage solution for a Power Utility Stations, Ultracapacitors is an exciting concept to bet on. They deliver energy quickly and can be recharged within seconds, and have a long life cycle. 
This paper hereby intends to bring up the qualities of Ultracapacitor as a redundant power supply and then defines an approach as to how this implementation can take an appreciable position in the context energy conservation and power management in the near future.

\section{MOTIVATION AND NEED}

More than thousands of substations installed say Utility substations, Weak transportation network and industries [5] nationwide require strategic investment for utility and maintenance. To improve the overall conversion efficiency or throughput of the entire substation, we require stand-by power [11] to avoid discontinuity in the substation performance in the extreme conditions of blackouts and brown-outs. In simple terms, we are continuously losing the availability of the power system measured on per year basis i.e. most of the power systems due to the power deficiency are not available to serve the power distribution and transmission. This availability is nothing but the mean time for which the power system is out of power. This can be mathematically represented as:

$$
\text { Availability }(\mathrm{A})=\mathrm{MTBF} /(\mathrm{MTBF}+\mathrm{MTTR})
$$

Where,

MTBF $=$ Mean time between failure.

MTTR = Mean time to repair (down time).

For ideal operation, Availability (A) should be $100 \%$. The stand-by supplies are specifically drawn upon to deliver power to the switching components and to power the substation control equipment at times of AC power outage. Thus it is obvious that the devices need to work well under a proper care and maintenance because unavailability of even single device in a substation unit due to power loss could possibly hamper the normal working of the Distribution subsystem.

Previously, because of limited energy storage and the inability to supply significant amounts of power, Ultracapacitors were utilized more to low-power applications such as memory stand-by for personal computers and real-time clocks. With more energy density than traditional capacitors, but less than that of a battery, they find their seat between the two technologies. Now, Ultracapacitors are being considered for a variety of highpower applications such as use in adjustable-speed drives, replacement of batteries for uninterruptible power supplies (UPSs), and for use in Electric Hybrid Vehicles [EHV].

The wide-spread interest in Ultracapacitor [16] is the result of a technological advance such that now Ultracapacitor have more energy-storage and power capability than ever before. In fact, Ultracapacitor are being compared to batteries. Practical applications that were once imagined solely within the domain of batteries are now being deeply looked over.
Thus there is an appealing requirement of the assisting redundant systems in power systems, so as to provide long term promising throughput of the Power distribution system.

\section{ANALYSIS OF ALTERNATIVES TO THE STAND-BY POWER SOURCE FOR SUBSTATION}

EPRI (Electric power research institute) and many assisting power domain companies conducted a survey to improve the design, performance, and maintenance of substation emergency power systems. EPRI has reported results of survey [12], and a study on utility practices for substation batteries, and measurements of loads at actual substations compared to loads projected during design. The analysis was given in regards to replacement or augmentation of lead-acid batteries (LABs) with new technologies when beneficial from a performance or cost view point.

The results focused in the survey [15] conducted by the institutions on the utility practices adopted for the sizing, installation, and maintenance of the substation's emergency energy stand-by system. This survey found that the dominant technology utilized for these systems is the vented lead-acid battery. Valve-regulated lead-acid (VRLA) batteries are still used at significant number of sites installed, but are generally being replaced with vented lead-acid systems due to continuously degrading life performance.

Most of the users seem to be contented with the vented leadacid batteries [18] (VLABs) which meet the 15-20 years of life cycle and the discharging requirements during the occasional AC power outage. However there observed were some issues regarding the performance of the batteries and the efforts taken for the proper and regular maintenance. The unfavorable feedback for the storage technologies received from the customers were more related to the preventive measures taken for their maintenance rather that for the technology itself making it hard quantify time and maintenance resources. Further this, the batteries lasted only for 5-6 years due to the continuous discharging and charging action in the Utility stations due to the fluctuating load requirements. One prime concern of the hour was also to know the healthiness and performance of the batteries. When vented lead-acid batteries could be monitored using electrolyte level and specific gravity measurement, the health of VRLA batteries could be accessed only by undergoing a full capacity test. This annoying experience has made variety of users reluctant to use newer technologies to replace traditional lead-acid batteries in this application.

The research report in [15] includes the monitoring of substation equipment to analyze the varying load profile in the Utility stations. Substations of different periods were embedded in the study, so that equipment change trend could be studied in a more sophisticated way. It was found that air and spring-controlled systems were used for switches and circuit breakers in older substations, they have been 
substituted by Motor (AC or DC) driven equipment in newer substations, for the reason that the later systems are much easier to install and maintain. The result is that the loads on modern substation power supplies are somewhat larger than on systems built 5-6 decades ago.

It is thus mandatory to consider the nature of the everchanging load profile. The dc/ac load profile in a substation is classified into three types by IEEE Standard 485[22], the sizing document for substation batteries.

\subsection{Continuous Loads}

Those loads remain energized all along throughout the battery duty cycle, such as relays, continuously operating motors, inverters, emergency lighting, energized coils, and control and communications systems.

\subsection{Non-Continuous Loads}

These loads are energized only during a segment of the battery cycle. These loads may come online at any time within the duty cycle, and may be ON for a due period and then become OFF automatically or by operator's action, or may continue till the end of the battery duty cycle. These loads include pump motors, ventilation motors, fire protection actuators, motor driven valves, and lighting etc.

\subsection{Momentary Loads}

These are loads which do come alive most of the times during the battery duty cycle, but last only for a short duration say 1 minute. Although most momentary loads last significantly for less than a minute, or even a second, it is customary to assume that the momentary loads last one minute because the initial voltage drop often determines the battery's 1-minute rating.

Momentary operations include switchgear and circuit breaker operation, motor-driven valves, isolating switches, field flashing of generators, motor starting currents, and inrush currents of transformers, switchover to redundant systems and so on.

The majority of the load increment has been observed in the substations has occurred significantly only in the Momentary loads. This suggests that the batteries or the power supplies have to be robust and overrated from an Ampere-Hour viewpoint so as to ensure that the batteries could maintain a healthy voltage level about the requisites of the fed system, which is determined by the low voltage electronics. Thus it is visible that there is an appreciable requirement of the power sources which can handle the large and instant current requirements for a brief period of time to serve the majority of momentary loads.

Inferring from the above discussion, the next step in our further research is to identify technologies which comply with the requirements for an energy stand-by system and evaluate them from technical and market perspectives to determine which has the most potential in this regard. In particular, we are looking for a technology which gives a system, which is easier to maintain and appreciate in terms of reliability, availability and robustness.

Nowadays the non-battery energy sources, such as Ultracapacitors, flywheels and fuel cells, also show some great potential in this area but need to be supplemented. Hence the hybrid systems of Ultracapacitors may make sense even with existing lead-acid batteries. A substation battery in general is sized according to a power profile, to ensure that it can support the current required by all loads that are likely to occur simultaneously, even if those loads last only for short time span. This type of over sizing may be sometimes not appreciable. An Ultracapacitor on the other hand, can more easily support high currents for a short period of time and can perform efficiently as per the load variation. Also they can withstand millions of chargedischarge cycles proving their resistance to fatigue.

Thus, it is possible to build a Battery-Ultracapacitor hybrid system significantly smaller than a lead-acid battery sized for the equivalent loads, capable enough to support a redundant system for power supply in a Utility substation.

\section{TIMELINE OF THE IMPLEMENTATION}

In the previous discussion so far, it has been observed that the High availability power systems is a prime concern of the hour. Current day design of a typical substation is supposed to be in a manner such that the data acquisition systems, monitoring devices like IED (Intelligent Electronic devices), RTU (Remote terminal unit) whose lively presence is a must to continuously have an eye over the events and faults going on in substation, should remain active all the way. Hence as a matter of requirement, a brief overview of the redundancy can be observed in the below diagram in Figure - 1 .

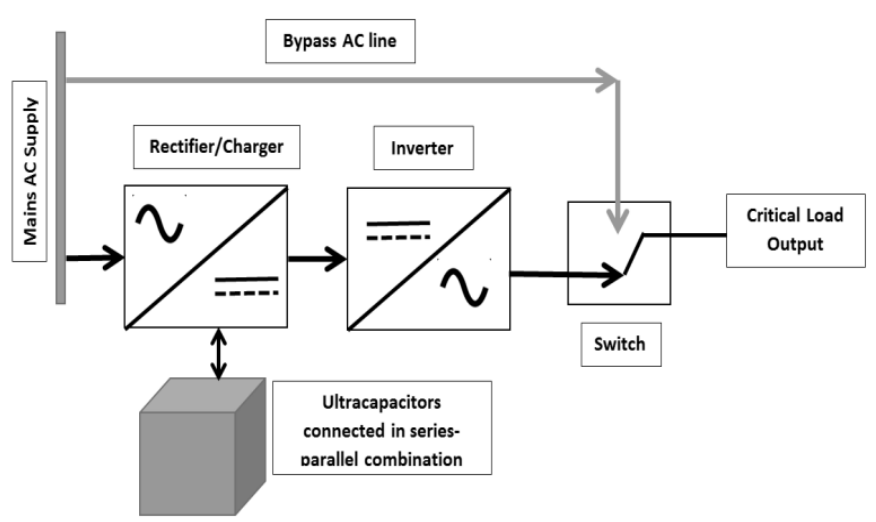

Fig- 1 Typical redundancy expected in a substation

The above figure shows that the stored energy source in this context will be an Ultracapacitor bank supplying the emergency power to the surrounding power systems.

The requirements and claims of the above system for a substation are as follows:

1) The Utilities will have a big Ultracapacitor bank with a bi-directional converter i.e. Buck-Boost 
Converter at the terminal to supply constant power output to the receiving devices.

2) All the protection and control devices will be connected through the secondary supply line to the output of the Ultracapacitor bank output which will get activated after the supply has been transferred from the mains $\mathrm{AC}$ power to the redundant power at the blackouts or power outage event.

3) Each redundant line can also have separate Ultracapacitor sources like as shown in figure in which two devices have individual source for redundancy connected by a Tie switch (Intelligent switch).

Now as previously in the section III has been justified, Ultracapacitors are thus expected to take care of the power system at times of deficient power due to their desirable qualities. Apart from power distribution, these are also expected to remain as a life line in the power generation as well. For these goals it is expected that the substation will have an Ultracapacitor bank in which several Ultracapacitors are in a series - parallel combination such that at the event of emergency, the power bank could fulfill the power requirement of the devices/grid.

\section{ARCHITECTURE FOR 1+1R STANDBY}

\section{POWER}

As far as standby power is considered, the architecture of the standby power source should be such that it has the nearly $100 \%$ availability for the critical load of the grid. This architecture should ensure the continuous presence of the $1+1 \mathrm{R}$ Standby system so that devices and system throughout the substation may remain safe all the time without idles for a while.

Hence the architecture of redundancy for the Ultracapacitor based Stand-by power setup is being explained which would fulfill the requirement of maintainability, fault tolerance and availability and functionality.

\subsection{Distributed Redundancy for Stand-By Power}

This configuration contains of individual stand-by power source for every bay and devices and there are no connections between two sources.

The goal of Distributed Redundancy is to keep/bring power system redundancy to every piece of terminal load equipment, as close as possible to the input supply terminals so that in case of the power outage in any one of the line/bay, can be powered by the another source which is not in use. This arrangement is helpful in providing High availability of the power systems in a substation as the equipment with no power will be instantly supported by the transparent switching with neighbor source to power it up and keep it alive always.

Below shown is the Figure-2 for the distributed redundancy with the Intelligent Tie Switches.

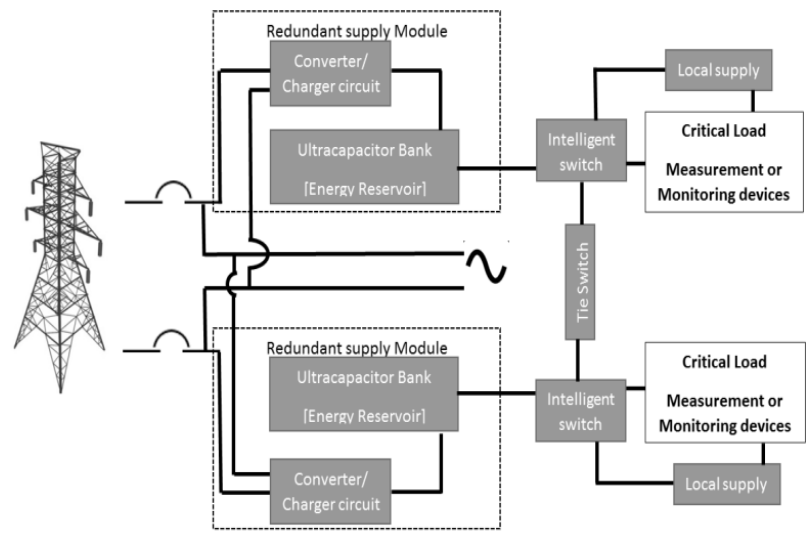

Fig-2 Distributed redundancy for a substation

\subsubsection{Key Advantages}

Distributed-Redundant systems provide a significant increase in terms of maintainability and fault tolerance compared to single module system, parallel redundancy or the isolated redundancy system. With such configuration, at extreme conditions even many bays or lines can be switched to one of the nearest redundant supply (which is not in use at the instant) on one of the bay and take the circuit breaker or failed devices for maintenance. This means that owner can very well organize the maintenance and thus the $100 \%$ availability could be achieved for the power systems. We can see the Tie switch connected between two redundant lines for the transfer of load between the interconnected lines. Its advantages are explained in the next section VIII.

\section{IEC 61850 COMPLIANCE}

The design of the substation proposed here suffices the claims and requirements of IEC Standard 62040-3 [Edition 2] [21] according to which the Uninterruptible supplies should be in such interconnection with the main power system such that the availability of the redundant power should be as high as $100 \%$.

The IEC 61850 suggest some of the below mentioned Logical Nodes [LN] [4] for different Node classes suitable for designing the proposed architecture for power based redundancy.

Some desired ones can be seen as below which will be handling the value of the primary logical nodes for the devices installed:

$\begin{array}{ll}\text { i) } & \text { PID Control: FPID } \\ \text { ii) } & \text { Physical health: LPHD } \\ \text { iii) } & \text { Alarm control: CALH } \\ \text { iv) } & \text { Synchronization controller: CSYN } \\ \text { v) } & \text { Action at over threshold: FXOT } \\ \text { vi) } & \text { Action at under threshold: FXUT } \\ \text { vii) } & \text { Voltage variation: QVVR } \\ \text { viii) } & \text { Auxiliary network: ZAXN } \\ \text { ix) } & \text { Battery system: ZBAT } \\ \text { x) } & \text { Converter: ZCON } \\ \text { xi) } & \text { Rectifier: ZRCT } \\ \text { xii) } & \text { Inverter: ZINV } \\ \text { xiii) } & \text { Battery charger: ZBTC }\end{array}$



xiv) Over-current: PTOC
Xv) Overvoltage: PTOV
xvi) Undercurrent: PTUC
xvii) Under-Voltage: PTUV

The logical nodes thus considered here are trusted nodes to determine the quality and operability of the stand-by power source to remain in communication with the Utilities with high availability as expected.

In the Figure- 3 below; given is the IEC 61850 based architecture for a substation having an alternate supply line for all the protection and control devices i.e. bay level devices connected to the stored energy source i.e. Ultracapacitor bank. The switchover from original to the redundant switches is taken care by Logical nodes in the IEC standard. While designing this backup power architecture, the plan of having the Tie switches between the nearest power sources or power supplies was also considered.

This is because it has been found useful that the power supplies which are not under operation could take over the nearby faulty bay or devices with the help of these Tie switches. These switches actually interact between the interconnected devices or bays for the purpose of maintaining the continuity of terminal load power in cases of fault and maintenance by transferring the load to other redundant supply module.

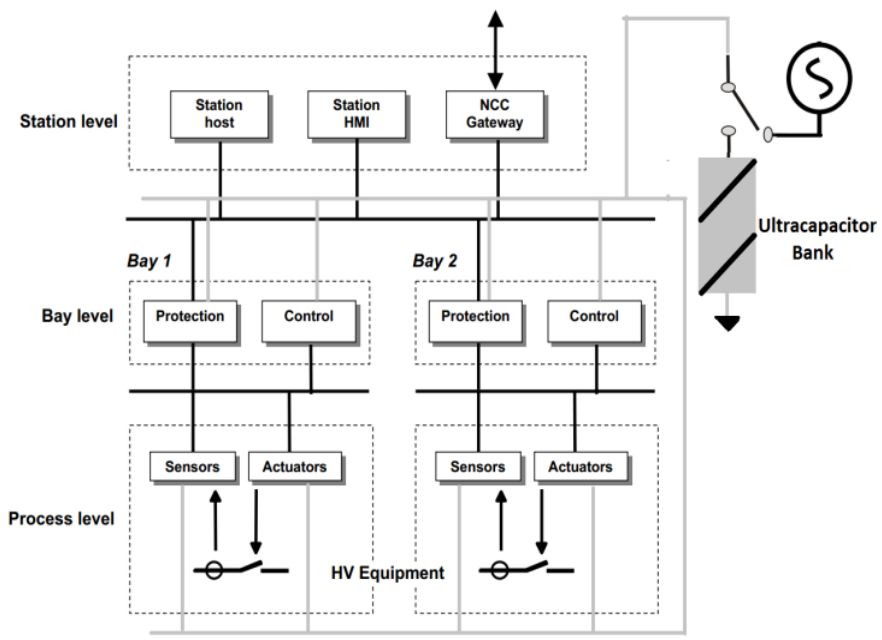

Fig- 3 IEC based substation architecture with stand-by power

\section{ULTRACAPACITOR: INTRODUCTION}

Ultracapacitor known as an electric double layer capacitor (16) (EDLC) is a new way of thinking about the energy storage which contains several advantages that battery and traditional capacitor cannot properly fulfill, such as fast charge and discharge, large capacity, long cycle life and other characteristics too.

Due to its promising performance, Ultracapacitor has been playing a great role in energy storage and wind power, and its huge application potential exist in many fields like electric vehicles, power systems, and waste energy harvesting applications and industrial etc. According to different manufacturing process technologies, Ultracapacitor can generally be classified as button-type (below 5 Farads), wound-type (5-200 Farads) and large-type (above 200 Farads).

\subsection{Ultracapacitor Model}

There are few model defined for Ultracapacitor which contain resistive and capacitive properties. Few of them had inductor also in the model but the classical equivalent design with a serial resistance and shunt resistance is typically considered ignoring its leakage current.

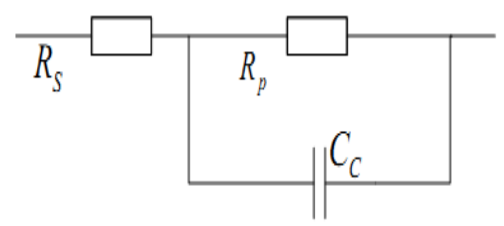

Fig-4: Ultracapacitor equivalent model

In Figure-4 above; Rs is serial resistor, means internal resistance of Ultracapacitor. $R_{p}$ is shunt resistor, stands for leakage current during static storage. $\mathrm{Cc}$ is the ideal equivalent capacitance.

\section{EXPLORING CAPABILITIES OF ULTRACAPACITOR FOR POWER STAND-BY SYSTEM}

Although high energy density of traditional batteries, it cannot be discharged deeply, and short life cycle, long discharge time, slow reaction to fluctuating power are its drawbacks. Ultracapacitor can overcome for the weaknesses of conventional battery. Figure- 6 shows the Current in Ultracapacitor, battery and load. Hybrid energy storage system can be established by battery combined with EDLC. Hybrid energy storage system [13] [10] based on EDLC is characteristic of fast charge and discharge speed, rapid reaction to fluctuant load current. When terminal load fluctuates, EDLC will suffer with most of the load current, so that the current rush across the battery is very small, under this condition, not only the energy consumed on resistance of battery gets decreased but also eventually improves the net battery service span/life.

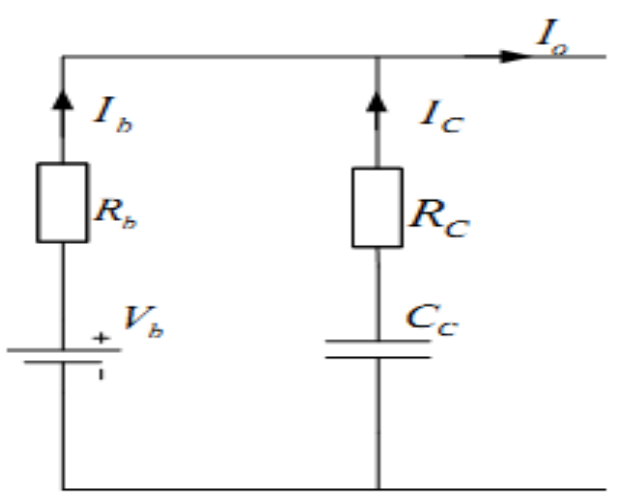

Fig - 5: Equivalent model of Hybrid system 


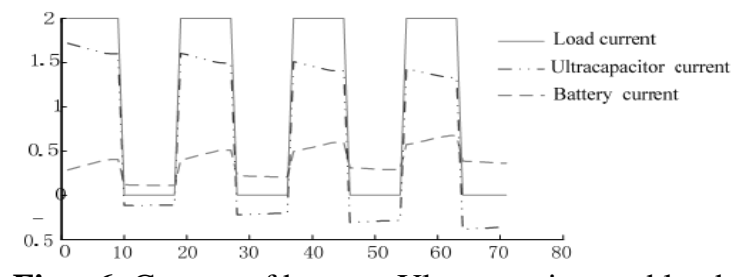

Fig - 6: Current of battery, Ultracapacitor and load

The hybrid energy storage system as shown in Figure-5 made up of battery and Ultracapacitor can obtain effective results in response to load pulse current and peak power output. The paper also analyzed energy savings and maximum extendable discharge time of hybrid energy storage system. The formulae are as follows:

Energy savings $\Delta \mathrm{W}$ formula can be represented as:

$$
\begin{gathered}
\Delta \mathrm{W}=\mathrm{R}_{\mathrm{b}} \mathrm{DI}_{\mathrm{o}}^{2}\left[\mathrm{~T}_{\mathrm{bo}}-(1-\epsilon) \mathrm{T}_{\mathrm{bc}}\right] \ldots \ldots(1) \\
\epsilon(\mathrm{D}, \mathrm{m})(\mathrm{f} \rightarrow \text { infinity }) \rightarrow(1-\mathrm{D}) \times \mathrm{R}_{\mathrm{b}} /\left(\mathrm{R}_{\mathrm{b}}+\mathrm{R}_{\mathrm{c}} / \mathrm{m}\right) .
\end{gathered}
$$

Maximum extend discharge time $\mathrm{T} \Delta$ formula:

$$
\Delta \mathrm{T} / \mathrm{T}_{\mathrm{bo}}=\varepsilon \delta \sqrt{\mathrm{D}} /(1-\varepsilon \delta \sqrt{\mathrm{D}})
$$

In the formula:

$\mathrm{R}_{\mathrm{b}}, \mathrm{R}_{\mathrm{c}}$ - Internal resistance of battery and internal resistance of Ultracapacitor

$\mathrm{I}_{0} \quad$ - Amplitude of output current

D - Duty cycle of the incoming current pulse

$\varepsilon \quad$ - Coefficient of energy savings

M - Ratio of total number of serial Ultracapacitors and shunt Ultracapacitors.

$\delta$ - Ratio ofload to the short circuit current in the battery bank.

Thus its credibility as well as the utility in a substation is justified in almost all aspects except few like the energy density limitation but that can be avoided by using the several Ultracapacitors in combination with the batteries like Lithium Ion batteries. Some new technologies are also going to approach market soon like Nanotube based Ultracapacitors [14] that will have very high energy density compared to current day Ultracapacitors.

\subsection{Characteristics of Ultracapacitor}

While traditional capacitors are rated in fractions of a farad, Ultracapacitors are rated in farads or hundreds and even thousands of farads. And, surprisingly energy density is not in the fractions of a joule, but thousands of joules. Ultracapacitor are devices which store energy in the form of separation of charge in the porous electrodes which increases surface area to accommodate more amount of charge. They can withstand a millions of charge/discharge cycles without wear and tear or loss in their performance. In addition, they are also similar to batteries in many respects; say the use of liquid electrolytes and the tradition of configuring various-sized cells into arrays to meet the power, energy, and output requirements for a wide range of applications.

Within Ultracapacitor, charge is stored electrostatically, not as chemical energy as in a battery (see Figure 7). They have an electrolyte solvent, typically potassium hydroxide (drain cleaner) or sulfuric acid (both aqueous electrolytes) and consist of two capacitors connected in series by the electrolyte. They are often called Electric double-layer capacitors [3] because of the two layers within the device, one at every electrode.

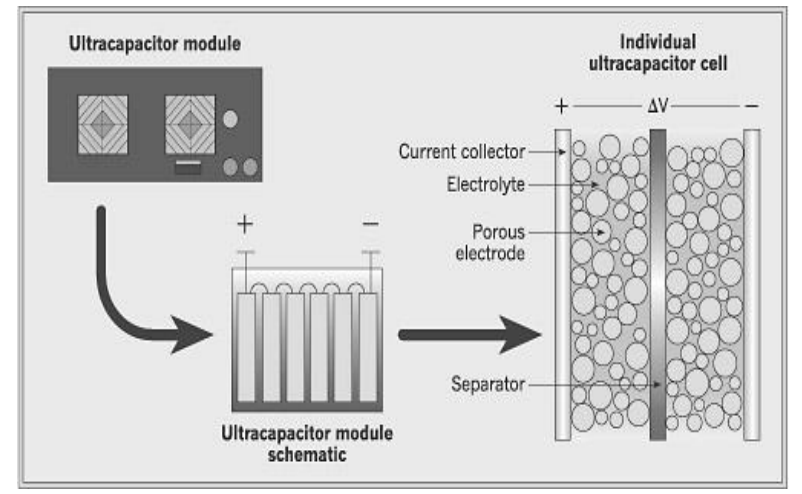

Fig - 7: Representative Construction of an Ultracapacitor (Borrowed from www.ecmweb.com)

Some advantages of Ultracapacitor [20] are:

- Highest capacitive density compared to any capacitor technology.

- Lowest cost per farad.

- Reliable.

- Long life cycle.

- Maintenance-free operation.

- $\quad$ Environmentally safe (Negligible emission)

- Wide operating temperature.

- High power potential.

- Fast charging (0.3 to 30 seconds) and fast discharging ( 0.3 to 30 seconds).

- $\quad$ High charge/discharge efficiency (0.85 to 0.98$)$.

Some disadvantages of Ultracapacitor are:

- $\quad$ Low cell voltage (around 2.7V per cell).

- Requires Voltage-balance circuit.

- $\quad$ High leakage current.

- High internal impedance.

- Discharge voltage is not flat, but exponential to zero.

\section{PERFORMANCE OF ULTRACAPACITORS}

\subsection{Effect of Temperature}

The temperature affects majorly to the internal resistance of the Ultracapacitor as is clearly visible in the graph below that resistance follows a down curve but capacitance remains almost same. Figure- 8 below depicts the performance in the operating temperature ranging from $-40^{\circ} \mathrm{C}$ to $65^{\circ} \mathrm{C}$.

The effect of temperature is thus two-fold: 


\subsubsection{Life}

High temperature will reduce the life cycle of the cell.

\subsubsection{Performance}

Extremely low temperature will raise internal resistance of the cell.

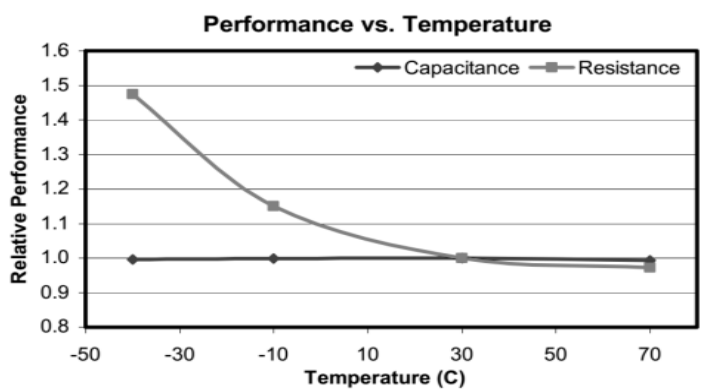

Fig-8 Temperature performance curve [Borrowed from Maxwell Technologies Product guide]

\subsection{Leakage Characteristics}

When an Ultracapacitor charges, the leakage current decays with time as the ions in the electrodes diffuse into the pores. The leakage current settles down to equilibrium value, which depends upon capacitance, voltage, and time parameters. Leakage current is proportional to the cell capacitance. As a thumb rule, equilibrium-leakage-current for Ultracapacitor at room temperature is $1 \mu \mathrm{A} / \mathrm{F}$. In Figure 9 below, capacitors having low capacitance have leakage currents of around 0.2 and $0.3 \mu \mathrm{A}$ after 150-160 hours. Leakage current increases with temperature. The settling time taken to approach the equilibrium value decreases with increased temperature as the ions diffuse more rapidly. Capacitors thus require an initial current to charge from $0 \mathrm{~V}$. This current ranges from 5 to $50 \mu \mathrm{A}$ for the variety of capacitors. The designers are thus supposed to choose capacitors according to their use and requirement for system current and voltage.

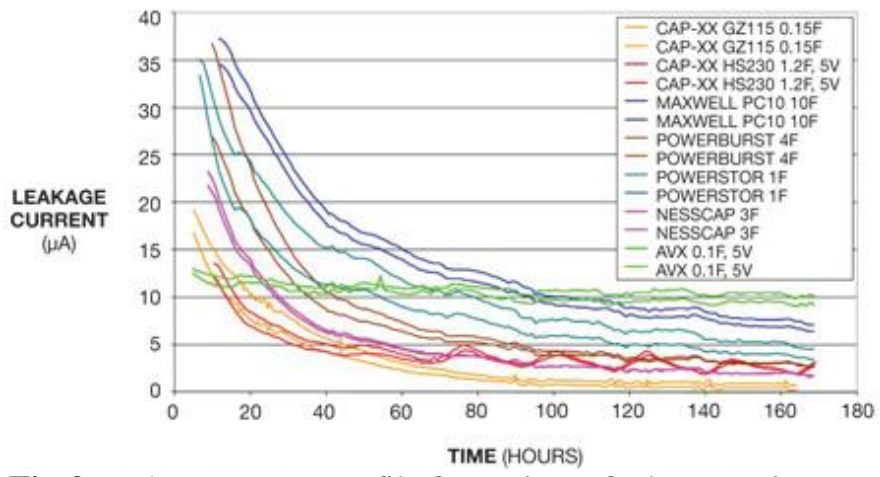

Fig-9 Leakage current profile for variety of Ultracapacitors

[2] [Borrowed from www.edn.com ]

\subsection{Frequency Response Characteristic}

The time constant $(\mathrm{T})$ of an Ultracapacitor is relatively much higher than that of an electrolytic capacitor and is around 1 seconds. Therefore, if exposed to a high frequency input,
Ultracapacitors may undergo overheating[6]. Therefore, Ultracapacitors can respond to short pulse power requirement, but due to the time constant the efficiency or available energy is reduced.

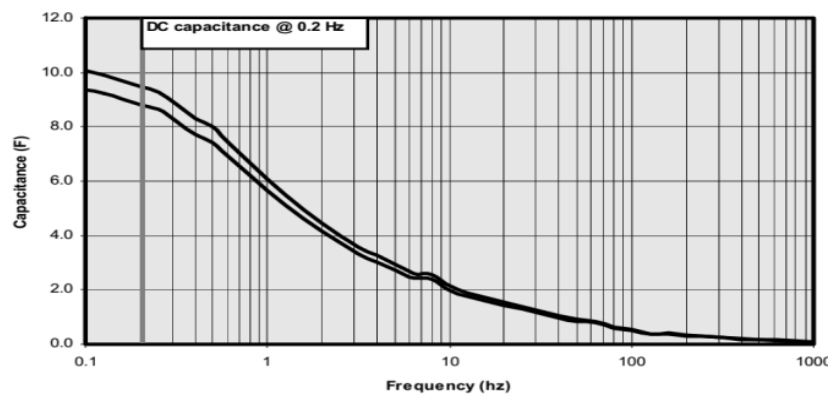

Fig-10 Ultracapacitor performance with frequency [Results borrowed from www.maxwell.com]

At very low frequency ( $\mathrm{f}<0.1 \mathrm{~Hz}$ ), the capacitance of an Ultracapacitor is almost constant with the temperature variations. This is clearly visible in the above Figure-10. It means that the ions penetrate to the depth of the pores in the electrodes regardless of the temperature say it be higher temperature. The capacitance is influenced by the temperature mainly in the frequency range between 0.1 and $10 \mathrm{~Hz}$ or above, which corresponds to the domain of operation. Thus the capacitance will be reduced as the incoming source has ripples of these frequencies.

Hence it is recommended to prevent the backup power source from the ripples to avoid malfunctioning of the Ultracapacitor Bank acting as a stand-by power source for the assisting power systems.

\section{DESIGNING THE ULTRACAPACITOR BANK-AN ENERGY RESERVOIR}

In order to function as a sophisticated and credible source of redundant power, an Ultracapacitor bank is required that the power bank should have following power electronics interface [8] charging (Stored energy mode) and discharging (Redundant mode) requirements properly fulfilled to provide the constant output power even in the event of fluctuating/noisy input:

Figure-11 below describes an arrangement for the bidirectional circuit which is capable of taking care of charging as well as discharging of the Ultracapacitor bank with an appreciable terminal voltage regulation.Figure-12 also depicts a conceptual picture of the Ultracapacitor bank based energy stand-by solution proposed in the paper. It consists of Ultracapacitor assembly denoted by "VBAT" and followed by Buck-boost converter [19], H-bridge converter, Filter circuit and finally AC transformer to supply AC power to the load. This seems to be an efficient and planned arrangement for power electronics interface for BatteryLoad interface in a substation (8). 


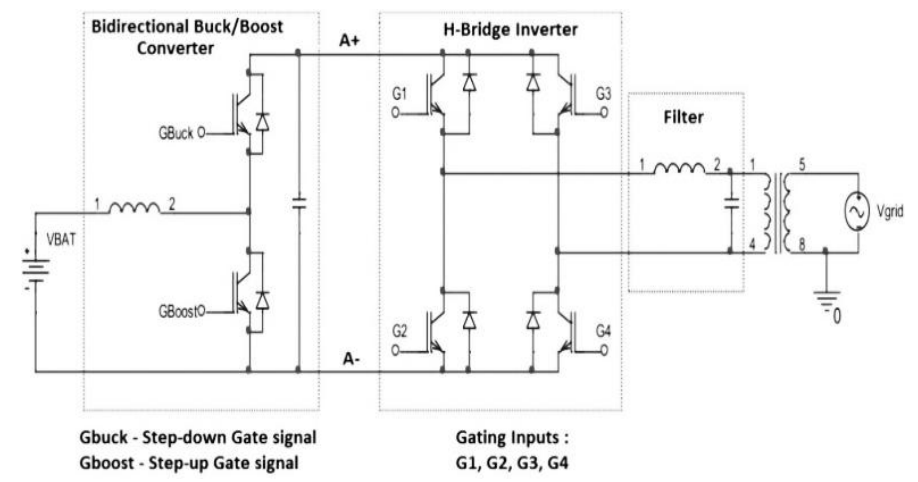

Fig-11 Bi-directional Buck-Boost Converter for Ultracapacitor Bank

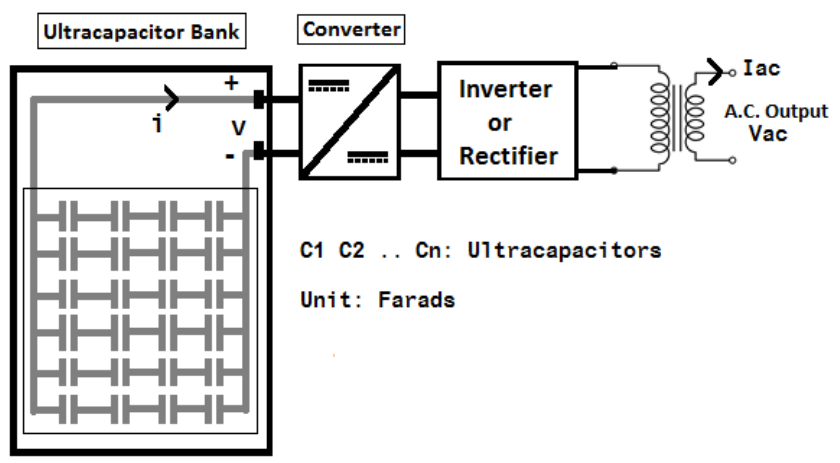

Fig- 12 Ultracapacitor assembly with converter interface

Hence the two modes of operation served by the circuit are:

\subsection{Discharge Mode}

In the very design of the power processing assembly, the $\mathrm{H}$ Bridge inverter in kept in series with a bidirectional DC-DC converter i.e. Buck-Boost Converter. In the discharge mode of power bank, the bidirectional converter is used to buck/boost i.e. Step-down or Step-up the terminal battery voltage to a level higher/lower compared to the output of the transformer so as to suffice the requirements of the current to flow from the bank to the grid. The inverter is needed in order to produce a chopped AC with ripple content. Hence this AC voltage is then passed through a filter so as to produce smooth AC signal. The current output now is passed into a step-up transformer which provides voltage stepped up to $120 \mathrm{~V}_{\mathrm{rms}}$ for directlyfeeding the grid.

Since the waveform of the AC voltage needs to begoverned and determined by the grid, the inverter unit should be of the current controlled inverter. A hysteresis controlled method would be a great concept to go with as it is easy to implement. This method works on the principle of conditional Gate terminal switching of the FET based switches to raise (boost) or lower (buck) the voltage as per the decisions made with reference to a thresholdvoltage level which does not allow the signal to cross the boundary conditions of voltage. In addition the buck/boost converter would be controlled by using a proportional-integral (PI) control strategy for controlling the bucking and boosting phenomenon.
On the basis of the concern that who is being fed by power bank, there can be two ways to think about the design.

i) $\mathrm{AC}$ Load: The output of the transformer will directly feed the AC load or the grid. The voltage requirement of the load can then be optimized according to the need by stepping the voltage up/down. After the output ac is available, if grid is considered as AC load, then the output AC should be made phase synchronized with the grid else for other loads can be fed directly.

ii) DC Load: This would require the DC regulated output from the Buck/Boost Converter i.e. Voltage $\boldsymbol{V}=(\boldsymbol{A}+)-(\boldsymbol{A}-)$ and the output DC level (V) can be adjusted according to the needs of the DC load going to be served.

\subsection{Charge Mode}

The Charge mode of the system makes use of the switches in the H-Bridge Inverter in which the free-wheeling diodes will make a bridge rectifier converting the ac to dc. Meanwhile the dc-dc converter takes care of regulating the amount of current that needs to be fed into the batteries. The battery charging can be accomplished through a PWM (Pulse width modulation based) charging method which control the amount of dynamic current flow to the power bank by sending a pulse with variable duty cycle decided as per the amount of current required for the input to the power bank to stay aloof from the current overloading. As an important point, the controlling of the Gate switches for the Inverter FET switches to turn on/off rectifying feature would be controlled also by an intelligent proportional-integraldifferential (PID) control to dynamically control the process according to the use of the circuit.

\section{POTENTIAL APPLICATIONS}

\subsection{Waste Energy Harvesting and Energy Savings}

The Ultracapacitor has tremendous capacity of storing energy for a long time without the noticeable loss. Hence the strength of the Ultracapacitor could be realized in the field of the energy harvesting in the renewable generation and also the waste energy from the industrial areas like heat, biomass and others could be used to generate electricity in the Ultracapacitor banks as suggested in the paper.

Considering a particular case in the power generation, the frequency transformer has been largely used in the industry, power and other fields. However, most of the frequency based control systems brake by lots of energy consumption, which result in tremendous waste, because energy come from braking is wasted in the form of heat on resistive elements, and the conversion efficiency of energy is decreased. Hybrid energy storage system based on the Ultracapacitors, connected to the DC bus of the converter can be used to store wasted energy come from braking. Hybrid system thus releases energy when energy in power system is insufficient to provide power support. 


\subsection{Enhance Performance in the DC Controlled}

\section{Systems}

DC system in substation is a part and parcel of relay protection, control system, communication, and accidental stand-by power supply. For most substations, lead-acid batteries are used as energy storage units, but it is charged and discharged by virtue of chemical reaction, the capacity of battery and efficiency of charge and discharge will decrease with increasing frequency of charging and discharging. In addition, the impurities present in electrolyte and self-discharge have adverse effect on conversion efficiency as well as on the life span of battery. Also leadacid batteries cannot instantly respond to the current pulse, which will result in huge loss of energy on internal resistance. Because Ultracapacitor has capability of fast reaction and rapid charge and discharge, traditional lead-acid battery and Ultracapacitor can be combined together to form a kind of hybrid energy storage system for enhancing power supply reliability of DC system as well as AC systems.

\subsection{Remote Installations}

Distant located power systems need reliable source of standby power to ensure a protected and predictable performance in the event of power outage in the utility, but regular maintenance to replace or repair the batteries or backup sources is difficult and expensive too. In this scenario, Ultracapacitors can thus suffice to the emergency power needs to get rid of the service discontinuity until the main power source of the Utility premises takes over.

\section{FEASIBILITY AND MARKET RESEARCH}

In accordance with the market research carried out by Transparency Market Research for 2013-2019 [1], the global Ultracapacitor market was around \$ 672.0 million in the year of 2012 and is expected to rise to $\$ 3,120.0$ million in coming year of 2019, growing at a Compound annual growth rate of $25.2 \%$ from 2013 till 2019. Asia has been the largest market holder for Ultracapacitors in the year 2012 due to the rising demand and huge potentials of Ultracapacitors in the domain of Automotive, Industrial, Power and energy, Military and Electronics too.

This market grab is due to the decreasing price and increasing applications in industries like HEV (Hybrid Electric Vehicle), energy storage systems, Distribution systems etc. In addition, government rules and regulations related to carbon dioxide emissions in areas such as Europe, North America and China is supporting the market scope of Ultracapacitors. In due course of time, benefit with Ultracapacitors like very high service life compared to the traditional batteries is expected to raise its demand in the years to come. Though the technology of Ultracapacitors is dated, yet it is at the nascence of its development. High price in comparison to the traditional batteries and less awareness among the customers in the industrial market is inhibiting Ultracapacitors' growth widely. However, as the price is coming down, it is expected that its market is going to grow instead of these negative impacts.

The market of the Ultracapacitors is also penetrating into the power sector firms. So the idea of having Ultracapacitors as stand-by power for substation may give an appreciable hike for the market

\section{ULTRACAPACITOR AS AN ECO- FRIENDLY TECHNOLOGY}

The growing trends and utter need of the environment friendly solution for energy is triggering the demand for alternative to the traditional sources like batteries as already discussed. But the older technologies had possibilities of emission of the green house gases in which utilities and industries are also responsible for extensive gaseous emission. Precisely, the GO GREEN strategy is primarily is a driving factor for the growth of the Ultracapacitors global market [23]. Governmental rules related to pollutants/carbon emissions are expected to sustain for a sufficient forecasted period of years, thus hopefully supporting in increasing demand of Ultracapacitors market globally in the coming years

\section{FUTURE IMPROVEMENTS}

In order to improve upon the conception of alternative power stand-by for substation devices, few favorable points could be considered:

1) Fast Automatic switchover to the redundant system.

2) Reducing the size of the Ultracapacitor for the same energy density.

3) Reducing the Leakage current from the Ultracapacitors in case if it is not in use.

4) These Ultracapacitor banks for energy storage could be charged using the environmental energy like Renewable or any alternative source of energy for e.g. solar, mechanical, Wind etc., thus giving a green solution for power distribution.

5) Currently Ultracapacitors have a limitation of energy density so we have to use them in combination with the batteries to have high power as well as energy density. So concepts like Nanotube [MIT Research] [14] may help us to generate high energy density Ultracapacitors.

Despite its less visibility of in the market, Ultracapacitors have found their way inside many applications like HEV (Hybrid Electric Vehicle)[7] [17], UPS (Uninterruptible power supply), and other charging applications for small electronic gadgets. So by introducing the above mentioned features considered for future, we expect the market of these capacitors to rise in a great pace as compared to now in context with the substations and power systems. 


\section{CONCLUSIONS}

The case study of the power based redundancy considered here can thus be summarized in following viewpoints:

1) The redundancy proposed for an IEC based substation in the current design suffices the requirements of continuous availability, reliability, fault tolerance and maintainability.

2) This technique is useful from the economic point of view because due to Ultracapacitor; energy can be safely stored and preserved for a long time with comparatively less chances of charge leakage unlike in the traditional batteries.

3) The power demand peaks due to overloading of the grid. This could be handled by having enormous charge storage in the Ultracapacitor bank which could also serve the momentarily lasting loads which require high inrush current just for few seconds or an instant.

4) The efficient Intelligent Tie switches as depicted in Figure-2 will help many critical loads to acquire power supply from their nearest stand-by source if the immediate backup source on the bay itself fails.

5) Ultracapacitor based systems have capability to undergo millions of charge/discharge cycles, making the system robust in its performance which is presently the major concern of the power domain companies.

6) Ultracapacitors will lead to the reduced carbon dioxide and toxic emission.

7) Due to high response time of Ultracapacitors it is fruitful to use them as redundant supplies because switchover from the Hot to the standby power supply will take hardly few milliseconds.

The conclusive points as summarized above imply that the technology of Ultracapacitor is way better than older technologies and can prove to be a better solution for hybrid systems which not only is of tremendous use in Utility stations but also in the field of Distributed generation in the Micro Grids hence adding more reliability to the current grid system and emerging power systems too. It also helps providing real-life cost savings.

\section{REFERENCES}

[1] Market research for Ultracapacitors: Transparency Market Researchhttp://www.prnewswire.com/newsreleases/ultracapacitors-market-is-expected-to-reachusd-31-billion-globally-in-2019-transparency-marketresearch-225479582.html.

[2] Leakage profile of Ultracapacitors:EDN.http://www.edn.com.

[3] Wikipedia: Electric double layer capacitor.

[4] IEC 61850 Standard. www.iec.ch.

[5] Alfred Rufer, Senior Member, IEEE, David Hotellier, Philippe Barrade, Member, IEEE, A SupercapacitorBased Energy-Storage Substation for VoltageCompensation in Weak Transportation Networks, IEEE Bologna power tech conference , June 23-26 ${ }^{\text {th }}$ 2013, Bologna, Italy.
[6] C.G.Liu, Frequency response characteristic of singlewalled carbon nanotubes as Supercapacitor electrode materialhttp://carbon.imr.ac.cn/file/Journal/2008/08_ APL_92_143108-LiuCG.pdf.

[7] Emil kalina, Applications of Ultracapacitors in electric and hybrid electric vehicles, Doctoral Degree Programme, Dept. of Electrical Power Engineering, FEEC, BUT.

[8] FredeBlaabjerg, Fellow, IEEE, Zhe Chen , Senior Member, IEEE, and SoerenBaekhoejKjaer, Member, IEEE, "Power Electronics as Efficient Interface in Dispersed Power Generation Systems", IEEE Transactions on power electronics, vol. 19, no. 5, September 2004.

[9] Kuldeepsahay, Bharti dwivedi, "Super capacitor based energy storage substation for power quality improvement".http://journal.esrgroups.org/jes/papers/ 5_4_8.pdf

[10] LijunGao, Roger A. Dougal, Shengyi Liu. Power Enhancement of an Actively Controlled Battery/Ultracapacitor Hybrid, IEEE Transactions on Power Electronics, Vol.20, No.1 (2005).

[11] Michael J. Thompson, Schweitzer Engineering Laboratories, Inc. David Wilson, McLaren, Inc. "Auxiliary DC Control Power System Design for Substations ".

[12] Palo Alto CA, Survey Results - Substation Batteries, EPRI, June 2003.

[13] R.A.Dougal, Shengyi Liu, Ralph E.White, Power and Life Extension of Battery-Ultracapacitor Hybrids.IEEE Transaction on Components and Packaging Technologies, Vol.25, No.1.(2002).

[14] Signorelli, Riccardo (Riccardo Laurea): Author, Joel Schindall and John KassakianHigh energy and power density Nanotube-enhanced Ultracapacitor design, modeling, testing, and predicted performance Massachusetts Institute of Technology, Dept. of Electrical Engineering and Computer Science. Issue 2009.

[15] Tom key, Steve Eckroad and Hareshkamath: EPRI Members "Assessment of alternatives to lead-acid batteries for substations".

[16] Yu Ling-yu, Feng Yu-ping, Supercapacitor Developments in the World, Electronic.(2008).

[17] Grid-Connected Hybrid Electric Vehicle EPRI Technical report, October 2002.

[18] White Paper: Design Advantages of Solid State Batteries versus Supercapacitors: Cymbet Corporation.

[19] TPS63060-EP: High input voltage buck-boost converter with 2a switch current: Texas Instruments India.

[20] Maxwell Technologies: BCAP0010 Ultracapacitor data

sheet.http://home.comcast.net/ hlandis0/photos/ucap2 600f.pdf.

[21] IEC Standard 62040-3 [Edition 2]: Uninterruptible power systems (UPS) - Method of specifying the performance and test requirements. 
[22] IEC standard 485: IEEE Recommended Practice for Sizing Lead-Acid Batteries for Stationary Applications.

[23] Ultracapacitors Market - Global Industry Analysis, Size, Share, Growth, Trends, And Forecast to 2019.http://www.wric.com/story/25338294/ultracapa citors-market-global-industry-analysis-size-sharegrowth-trends-and-forecast-to-2019.

\section{BIOGRAPHY:}

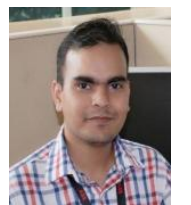

Vasuki soni : Author is an undergraduate from National Institute of Technology, Raipur (Chhattisgarh) India in the discipline of Electronics and telecommunication engineering. He is now working as an engineer in $\mathrm{ABB}$ Global Industries and Services Limited, Bangalore (karnataka) India. 